\title{
Sociedade da Informação e as mídias sociais no contexto da comunicação científica
}

\section{Information Society and social media in the context of scientific communication}

\author{
Natalia Rodrigues Delbianco ${ }^{1}$, Marta Lígia Pomim Valentim² \\ ${ }^{1}$ Universidade Estadual Paulista (UNESP), Marilia, São Paulo, Brasil. ORCID: https://orcid.org/0000-0002-0723-2379 \\ 2 Universidade Estadual Paulista (UNESP), Marilia, São Paulo, Brasil. ORCID: https://orcid.org/0000-0003-4248-5934
}

Autor para correspondência/Mail to: Natalia Rodrigues Delbianco, nathdelbianco@gmail.com

Recebido/Submitted: 06 de janeiro de 2021; Aceito/Approved: 18 de maio de 2021

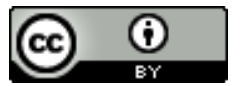

Copyright (c) 2022 Delbianco \& Valentim. Todo o conteúdo da Revista (incluindo-se instruções, política editorial e modelos) está sob uma licença Creative Commons Atribuição 4.0 Internacional. Ao serem publicados por esta Revista, os artigos são de livre uso em ambientes educacionais, de pesquisa e não comerciais, com atribuição de autoria obrigatória. Mais informações em http://revistas.ufpr.br/atoz/about/submissions\#copyrightNotice.

\begin{abstract}
Resumo
Introdução: A Sociedade da Informação está alicerçada no tripé "informação", "tecnologias de informação" e "telecomunicação", cujos fenômenos são estudados por diferentes campos científicos, entre eles a Ciência da Informação. Este artigo busca compreender os impactos da denominada Sociedade da Informação no contexto da comunicação científica. Como objetivo principal investiga como os avanços tecnológicos e o uso de mídias sociais influenciaram os Estudos Métricos da Informação em relação à Altmetria. Discute sobre a Sociedade da informação, a informação e a tecnologia, apresentando alguns dados sobre as mídias sociais e as redes sociais. Método: Em relação à metodologia, adota uma abordagem descritiva-exploratória, de natureza qualitativa, com base em revisão de literatura. Resultados: Considera que os avanços tecnológicos podem ser utilizados tanto positivamente, quanto negativamente, mas, de um modo geral, ajudam no desenvolvimento da ciência e no compartilhamento da informação, porque os canais utilizados para tal disseminação foram significativamente ampliados e, desse modo, resultaram no surgimento de um novo subcampo dos Estudos Métricos, visando justamente estudar os fenômenos desses novos canais de divulgação científica. Conclusão: Por fim, entende que o desenvolvimento da ciência com base nas tecnologias, em especial na comunicação por meio das mídias sociais, faz com que a Ciência da Informação esteja em constante avanço, sendo a Altmetria o resultado da ampliação da comunicação da ciência em meios tidos como não formais.
\end{abstract}

Palavras-chave: Sociedade da Informação; Tecnologia; Comunicação Científica; Mídias Sociais; Redes Sociais; Altmetria.

\begin{abstract}
Introduction: The Information Society is based on the tripod "information", "information technologies" and "telecommunications", whose phenomena are studied by different scientific fields, including Information Science. This article intends to understand the impacts of called Information Society in the context of Scientific Communication. The main objective is to investigate how technological advances and the use of social media influenced the Metric Studies of Information in relation to Altmetrics. It discusses the Information Society, information and technology, presenting some data on social media and social networks. Method: It adopts a descriptive-exploratory approach of a qualitative nature, based on a literature review. Results: As a result, it considers that technological advances can be used both positively and negatively, but, in general, they help in the development of science and the sharing of information, because the channels used for such dissemination have been significantly expanded and, thus, resulted in the emergence of a new subfield of Metric Studies, aiming recisely to study the phenomena of these new channels of scientific dissemination. Conclusions: Finally, it understands that the development of science, based on technologies, especially communication through social media, causes Information Science to be in constant advance, Altmetrics being the result of the expansion of science communication in media considered as non-formal.
\end{abstract}

Keywords: Information Society; Technology; Scientific Communication; Social Media. Social Networks; Altmetrics.

\section{INTRODUÇÃO}

A informação se torna um elemento muito importante para a sociedade atual e, sendo assim, as discussões acerca do que é informação marcam o desenvolvimento da Sociedade da Informação que, por sua vez, está alicerçada em um tripé composto por informação, tecnologia de informação e telecomunicação.

No que diz respeito ao conceito de Sociedade da Informação, destaca-se que existem distintas nomenclaturas e compreensões como, por exemplo: "Sociedade do Conhecimento", "Sociedade da Informação e do Conhecimento" e "Sociedade em Rede", que por vezes são utilizadas como sinônimos, conforme explicam Dziekaniak e Rover (2011) quando destacam os conceitos de Sociedade em Rede, Sociedade do Conhecimento, Sociedade Líquida, Modernidade Líquida, entre outros. Neste artigo optou-se por utilizar a expressão "Sociedade da Informação" considerando os estudos de Mattelart (2002) e Ilharco (2003).

Mattelart (2002) destaca a compreensão de Bell sobre Sociedade da Informação: "Cada sociedade é uma sociedade de informação e cada organização é uma organização de informação, assim como cada organismo é um organismo de informação [...]" (Bell, 1979, p. 169 apud Mattelart, 2002, p. 85). Ilharco (2003, p. 75) compreende Sociedade da Informação como aquela que reside "[...] sob o prisma da informação, das tecnologias de informação e comunicação". 
A Revolução Industrial foi essencial para que ocorresse uma mudança na sociedade, uma vez que trouxe muitos avanços, enfoca-se em especial a terceira Revolução Industrial, denominada de "Revolução Técnico-Científica" ou "Revolução da Informação" que ocorreu em meados do Século XX, após a Segunda Guerra Mundial, cujas características estão inter-relacionadas ao avanço tecnológico abrangendo o setor produtivo (indústria) e a academia e, assim, alterou as relações sociais e econômicas, uma vez que a economia passa a ser baseada na informação e na tecnologia.

Os avanços tecnológicos e a quantidade de informação produzida influenciaram o avanço das Tecnologias da Informação e Comunicação (TIC), bem como o surgimento de ambientes digitais de comunicação. Com a consolidação da Web 2.0, as mídias sociais ganharam mais espaço e, assim, surgem as redes sociais, listas de discussões, portais de vídeo, entre outros. Kemp (2021) destaca que, atualmente, quase 60\% da população mundial está conectada à rede Internet.

Nessa perspectiva, a Ciência da Informação (CI), que estuda os fenômenos referentes à informação em diferentes contextos e ambiências, também passa a estudar a informação no contexto científico e, nesse âmbito, a comunicação científica, que engloba questões sobre o compartilhamento da informação, a mensuração e quantificação das produções científicas e seus impactos na ciência e na sociedade. Como parte desses desenvolvimentos, surgem os Estudos Métricos da Informação (EMI) que, por sua vez, desenvolvem e aplicam métodos e técnicas visando mensurar os impactos causados pelos avanços tecnológicos e desenvolvimento da Web na ciência, conforme destacam Oliveira e Gracio (2011, p. 19) tais estudos fazem a avaliação da informação "[...] em diferentes suportes, baseados em recursos quantitativos como ferramentas de análise".

Nesse sentido, a pesquisa tem como objetivo principal investigar, de modo geral, como os avanços tecnológicos e o uso das mídias sociais no contexto da comunicação científica influenciaram os EMI na criação do seu mais recente subcampo métrico, a Altmetria. Dessa maneira, vale debater sobre a Sociedade da Informação, a informação e os avanços tecnológicos, no intuito de apresentar suas características gerais e alguns dados atuais sobre as mídias sociais e as redes sociais.

Para alcançar tal objetivo, a pesquisa adota uma abordagem descritiva-exploratória, de natureza qualitativa, com base em uma revisão de literatura. Gil (2008, p. 28) afirma que as pesquisas descritivas "[...] têm como objetivo primordial a descrição das características de determinada população ou fenômeno ou o estabelecimento de relações entre variáveis", e complementa que as pesquisas exploratórias visam o desenvolvimento de ideias e conceitos, bem como abrem espaço para a possibilidade de esclarecimentos e modificações.

\section{SOCIEDADE DA INFORMAÇÃO E AS TECNOLOGIAS: UMA ABORDAGEM INICIAL}

A denominada "Sociedade da Informação" ganha espaço durante o período em que ocorre a Revolução Industrial, mas é na terceira fase da Revolução Industrial, conhecida como "Revolução Técnico Científica" ou "Revolução da Informação", que a economia passou a ser baseada na informação, na tecnologia e nas telecomunicações, conforme mencionado anteriormente. A Sociedade Pós-Industrial, na concepção de Mattelart (2002), se refere a uma sociedade na qual há um jogo entre as pessoas, o que difere até então da Sociedade Pré-Industrial (contra a natureza) e da Sociedade Industrial (natureza fabricada).

Destaca-se que o período que abrange a Segunda Guerra Mundial e a Guerra Fria trouxe transformações marcantes, como o avanço dos meios de comunicação, colaborando para a produção e para a disseminação de informações, incluindo as informações de cunho científico, e isso graças ao desenvolvimento das TIC. Ilharco (2003, p. 108) explica que as TIC "[...] são assim tomadas como um instrumento, uma ferramenta que funciona como apoio, para desenvolver ou organizar algo - 'a tecnologia de informação é um instrumento'". A Sociedade da Informação é discutida por diversos autores desde então, entre eles Mattelart (2002) que, por sua vez, destaca a significativa contribuição de Daniel Bell, mencionando que foi este pesquisador que apresentou o termo pela primeira vez no final dos anos 1970, demonstrando a informação como um elemento essencial para uma sociedade, uma organização e, até mesmo, para uma pessoa. Complementando, Ilharco (2003) destaca que a Sociedade da Informação foi gerada pela Revolução da Informação, e se consolida como o mais rápido desenvolvimento tecnológico da humanidade.

Questionamentos acerca do que é a informação fazem parte e marcam a consolidação da Sociedade da Informação, ou seja, é a imprecisão da noção de informação que abre espaço para a constituição da Sociedade da Informação (Mattelart, 2002). Nesse sentido, é importante ter uma percepção sobre o que envolve o fenômeno "informação" e, ao mesmo tempo, compreender que se trata de um conceito complexo ainda hoje discutido. Destaca-se que, no contexto dessa sociedade e da própria informação, está situada a CI, que estuda os fenômenos inter-relacionados à informação, em diferentes contextos e ambiências, bem como aspectos vinculados à sua comunicação e ao comportamento dos usuários em relação a ela. Entre as suas características pode-se mencionar a

[...] preocupação não com a custódia, a posse de documentos, mas com a sua circulação, sua disseminação, a promoção de seu uso de maneira mais produtiva possível. Depois, o foco não 
propriamente nos documentos (registro físico) mas em seu conteúdo ou, dito de outro modo, na informação contida nos documentos C. A. Á. Araújo (2014, p. 10).

O conceito de informação não é consenso na área de CI, uma vez que é compreendido pelos pesquisadores de distintas maneiras, dependendo dos fundamentos teóricos do qual se parte, bem como dependendo do contexto em que se está investigando. Tradicionalmente a informação é vista como um conjunto de dados que, a partir da atribuição de significado por um sujeito cognoscente, passa a ser compreendido e, portanto, torna-se uma informação. Uma outra visão se refere às correntes matemáticas oriundas da Teoria Matemática da Informação ${ }^{1}$, que se refere à quantificação, à medição e ao armazenamento da informação.

Partindo das considerações dos autores Mattelart (2002) e Ilharco (2003), a informação pode ser compreendida como um fenômeno resultante da interpretação de um sujeito cognoscente, nesse sentido, quando não faz sentido para um indivíduo, continua sendo um conjunto de dados, entretanto, enfatiza-se que mesmo que seja um conjunto de dados, este não pode ser desprovido de significado, porque não existem dados sem significado algum. Por fim, Ilharco (2003, p. 179) afirma que a informação "[...] é algo que nos foi dado e que de acordo com nós mesmos faz a diferença face à possibilidade de não nos ter sido dado". Complementando as afirmações anteriores, Tomaél (2012, p. 15) explica a informação como:

[...] um processo de formação de sentidos dos fatos - resultante do saber, dos acontecimentos, das especulações, das ações e dos projetos -, cujo conteúdo permutamos com o ambiente em que estamos inseridos. A informação pode confirmar fatos e tendências, gera a acumulação do conhecimento, construindo memória. Propaga-se no tempo e no espaço, e, para se tornar pública, utiliza os meios de comunicação.

A quantidade de informação que é produzida no mundo aumenta cada vez mais, e com o auxílio das tecnologias passa a circular livremente na sociedade, de modo que não conhece limites ou fronteiras. Ilharco (2003) explica que as TIC propiciaram diferentes experiências humanas, pois transformam a realidade vivenciada pelo indivíduo. Assim, "[...] a informação tecnológica é o resultado de muitos e variados instrumentos e objeto da nossa atenção e sobretudo da nossa acção" (Ilharco, 2003, p. 79).

A imersão nas TIC faz com que se tenha uma certa dependência delas, até mesmo para tarefas mais simples do dia a dia, inclusive elas têm o poder de substituir alguns serviços. A tecnologia se transforma em um instrumento que fica à disposição de cada ser humano, e com ela é possível se conectar e se relacionar a quase tudo que existe e, assim, pode incluir o ser humano em uma realidade que nunca antes foi vivenciada.

No mundo tecnológico e com tanta informação disponível aos usuários, há distintos aspectos referente à veracidade dos conteúdos disseminados e, sendo assim, muitos problemas informacionais advêm desse contexto. Atualmente grande parte da sociedade está conectada à Rede Internet, utilizando sobretudo as redes sociais, portanto, não se pode ter o controle de tudo o que ocorre nesse ambiente, de todos dados que estão sendo disseminados e coletados, de todos os clicks realizados, de todas as ações feitas por um indivíduo ou, ainda, como esses dados estão sendo utilizados por programadores, organizações etc.

Os avanços das TIC podem trazer efeitos negativos e/ou positivos à sociedade. Sabe-se, por exemplo, que tais avanços influenciaram guerras. Hardt e Negri (2004) afirmam que é a partir do desenvolvimento tecnológico, no que diz respeito às armas, que a guerra alcança dimensões absolutas, uma vez que se atinge a destruição em massa, expandindo a morte para todos os seres humanos. O filme "Ponto de Mutação"2 (1990), dirigido por Fritjof Capra, destaca esse aspecto, a partir da interpretação da cientista, personagem criado por Capra, que recorda que suas descobertas científicas poderiam levar à produção de armas perigosas.

Por outro lado, há pontos positivos como, por exemplo, a otimização do tempo, automatização de tarefas, buscar e obter informações com velocidade, tanto no âmbito profissional, quanto no âmbito acadêmico e/ou pessoal. Contudo, mesmo com toda a facilidade e rapidez de se trabalhar a informação e com os recursos tecnológicos disponíveis, a otimização do tempo pode resultar, entre outras coisas, na ansiedade de informação. Sobre o fenômeno da ansiedade de informação, Braga (2016, parágrafo 30) afirma que ela pode acontecer porque os usuários querem apreender muitas informações ao mesmo tempo e isso "[...] prejudica a capacidade de fixação mnemônica dessas informações e, consequentemente, a consolidação do aprendizado." Assim, como agora tudo pode ser conseguido de modo mais rápido, o indivíduo não consegue lidar com a ideia de esperar muito para obter as informações que precisa, ao mesmo tempo, também não considera passar muito tempo sem "estar conectado", com diferentes objetivos.

Vale destacar uma questão que está voltada ao desenvolvimento pessoal do indivíduo, isso porque para lidar com a constante atualização e avanço tecnológico, as pessoas em geral não possuem todas as competências e habilidades necessárias para trabalharem com essas novidades, e com as novas ferramentas disponibilizadas. Nesse sentido, os indivíduos se deparam com a necessidade constante de se capacitarem. Do mesmo modo, no

${ }^{1}$ A Teoria Matemática da Informação estuda a quantificação, armazenamento e comunicação da informação. Proposta por Claude E. Shannon em 1948, visando identificar os limites referentes ao processamento de sinais e operações de comunicação.

${ }^{2}$ Filme adaptado da obra de Fritjof Capra "O ponto de mutação: a Ciência, a sociedade e a cultura emergente". 
que se refere às organizações, Ilharco (2003) menciona que é preciso que o desenvolvimento das competências tecnológicas e informacionais aconteça internamente de modo constante.

Isto posto, destaca-se que, atualmente, as máquinas tecnológicas podem, a partir de algoritmos, manipular os indivíduos e até aliená-los, uma vez que alguns códigos e algoritmos criados para melhoria das máquinas e das ferramentas, em alguns casos, são tão complexos que podem prever os passos e os comportamentos dos seus usuários. Guattari e Micropolítica (1996), na obra intitulada "Micropolítica: cartografia dos desejos", trabalham com a produção da subjetividade, limitação dos desejos, cultura como mercadoria, mas o destaque a ser feito aqui diz respeito a uma breve análise referente ao próprio título. Ao passo que a tecnologia está presente em todos os lugares, e em diversos momentos, não só as ações das pessoas passam a ser registradas e localizáveis, como também suas preferências pessoais, seus desejos, e pode ser que em alguns casos esses desejos sejam impostos de tal forma que cada indivíduo os aceita como sendo dele próprio. Retomando a ideia da falta de controle sobretudo no que se refere ao que é produzido e coletado no ambiente Web.

Nessa perspectiva, o empresário Tristan Harris faz uma reflexão pertinente no que diz respeito ao uso da tecnologia e aos avanços tecnológicos em um documentário lançado pela rede de streaming Netflix, denominado "O Dilema das Redes" (2020). Nele o empresário destaca que "[...] não é que a tecnologia em si seja uma ameaça existencial, é a capacidade da tecnologia de trazer à tona o pior da sociedade, e o pior da sociedade é uma ameaça existencial".

Ao mesmo tempo em que a tecnologia prejudica e causa problemas ao ser humano, essa reflexão mostra que a sociedade em si é também problemática, e precisa lidar com questões políticas, problemas econômicos e sociais, guerras, lacunas na educação e cultura, além englobar em sua rede os próprios indivíduos que carregam suas próprias crenças e valores.

O avanço da Sociedade da Informação, no que diz respeito às TIC e uso da Web, influenciaram, como já mencionado, no desenvolvimento das mídias sociais e das redes sociais, assim na próxima subseção será abordado um panorama sobre elas.

\section{VISÃO GERAL DAS MÍDIAS SOCIAIS E DAS REDES SOCIAIS}

Inicialmente é necessário esclarecer que há diferença entre mídia social e rede social, portanto não são termos sinônimos, apesar de estarem inter-relacionados. Mídia social é um termo mais amplo e, portanto, engloba diferentes mídias, nas quais é possível transmitir e trocar informação com outros indivíduos, ou seja, as mídias sociais oferecem as condições tecnológicas necessárias para que haja a interação entre as pessoas.

Kaplan e Haenlein (2010) definem mídias sociais como um grupo de aplicações para a rede Internet, construídas a partir dos fundamentos ideológicos e tecnológicos da Web 2.0, que possibilitam a criação e a troca de conteúdo. Segundo Kotler e Keller (2012), as mídias sociais podem ser classificadas em três tipos: comunidades e/ou fóruns online, bloggers e redes sociais.

De outro modo, as redes sociais se referem a forma de conectar as pessoas, melhorar a conexão entre elas, possibilitando que haja compartilhamento de informação, seja entre pessoas ou entre empresas, ou entre pessoas com empresas. Toda rede social existente na Internet é uma mídia social. Marteleto (2010, p. 30-31) explica que há dois níveis referentes às redes sociais:

1. As redes primárias, relativas às interações cotidianas entre as pessoas (familiaridade, parentesco, vizinhança, amizade, etc.) no processo de socialização. Trata-se de processos autônomos, espontâneos e informais.

2. As redes secundárias, formadas pela atuação coletiva de grupos, organizações e movimentos que defendem interesses comuns e partilham conhecimentos, informações e experiências orientados para determinados fins.

Recuero (2016, p. 29) explica que rede social se refere a:

[...] interação, é troca social. É um grupo de pessoas, compreendido através de uma metáfora de estrutura, a estrutura de rede. Os nós da rede representam cada indivíduo e suas conexões, os laços sociais que compõem os grupos. Esses laços são ampliados, complexificados e modificados a cada nova pessoa que conhecemos e interagimos.

Musso (2006, p. 34) define redes sociais como "[...] uma das formas de representação dos relacionamentos afetivos, interações profissionais dos seres humanos entre si ou entre seus agrupamentos de interesses mútuos".

Ainda, pode-se complementar que é uma estrutura formada por pessoas que visam estabelecer relacionamentos e se aproximarem com base em seus interesses comuns, nesse sentido podem operar em diversos níveis, como entretenimento, relacionamento e profissional (Resultados Digitais, 2020). Se faz importante mencionar que, 
a ideia de rede social não é nova na sociedade, independente do mundo digital, uma rede social refere-se ao estabelecimento de relações entre indivíduos com valores e interesses similares.

O uso da Internet e das mídias sociais vem crescendo significativamente e, com isso, atualmente é possível se conectar com pessoas e dispositivos de várias partes do mundo, ou seja, o estabelecimento de relações sociais ocorre devido ao aumento do uso das mídias sociais.

Buscando apresentar um panorama em relação ao uso da Internet no mundo, destacam-se alguns dados de uma pesquisa realizada por Kemp (2021), consultor da We Are Social, a qual evidenciou que a quantidade de usuários utilizando a Internet no mundo em janeiro de 2021, era de 4,66 bilhões, equivalente a um aumento de $7,3 \%$ se comparado a janeiro de 2019.

Por outro lado, a quantidade de usuários de mídias sociais em âmbito global, em janeiro de 2021 era de 4,20 bilhões, quantidade que, ao ser comparada a janeiro de 2020, evidenciou um aumento de $13 \%$. Em relação a todos os usuários da Internet no mundo, cerca de mais de 5,22 bilhões de pessoas agora usam os telefones móveis para se conectarem. A partir dessa pesquisa, Kemp (2021) demonstrou que cerca de 59,9\% da população mundial já estava conectada à rede Internet, mas, por conta da pandemia causada pelo vírus COVID-19, os números podem ser maiores. Kemp (2020) afirmou que, segundo as últimas tendências e pesquisas, até meados de 2020 mais da metade da população utilizará meios de comunicação social, fato este confirmado por Kemp (2021), ao constatar que cerca de $53 \%$ da população já utiliza os meios de comunicação social, tal como havia sido previsto.

Outro aspecto relevante diz respeito ao tempo de uso, que em comparação a 2020 também aumentou, Kemp (2021) demonstra que a média que os indivíduos ficam conectados online é equivalente à aproximadamente sete horas por dia. No Brasil, a média registrada fica em torno de 10 horas por dia, sendo o segundo país em que as pessoas passam mais tempo conectado à rede.

As redes sociais, assim como as tecnologias de um modo geral, também trazem desvantagens e podem acarretar problemas para as pessoas, como exemplo podem-se mencionar problemas com a segurança dos dados, a veracidade dos dados (fake news), padrões de comportamento e beleza, entre outros. Por isso, alguns estudos acerca desses problemas parecem ganhar espaço na sociedade. Nessa perspectiva, destaca-se o livro de Jaron Lanier $(2018)^{3}$, intitulado "Dez argumentos para você deletar agora suas redes sociais", no qual disserta sobre dez problemas comuns enfrentados por usuários das redes sociais. Entre os motivos destaca que as redes sociais fazem com que seus usuários percam o livre-arbítrio, alteram a capacidade de ter empatia e, até mesmo, interferem nos sentimentos e emoções.

Em contrapartida, também, é possível perceber pontos positivos, como criar relações sociais, trabalhar com aspectos culturais e artísticos, utilizá-las no âmbito organizacional, institucional e empresarial para a divulgação de uma marca, produto e ou serviço, auxiliar no processo de educação. Desse modo, elas podem ser benéficas para a disseminação da informação. Tomaél, Alcará, e Di Chiara (2005) entendem que as redes sociais podem ser consideradas como uma das estratégias utilizadas para o compartilhamento de informação e conhecimento na sociedade, porque medeia as relações entre as pessoas que dela participam, fazendo com que o indivíduo consiga delinear e expandir sua rede, na medida em que se insere no contexto social.

De modo geral, o uso de tecnologias, bem como das mídias sociais e suas redes sociais fazem parte do que, segundo afirmam Reis e Tomaél (2017) ser um processo natural da sociedade e que os indivíduos que não se adaptam a esta realidade acabam sendo "deixados de lado" e excluídos de grupos sociais.

Conhecidos esses dados, percebe-se que o uso dessas tecnologias faze parte da vida de cada indivíduo, e até mesmo auxilia no desenvolvimento de relações entre eles, além de apresentarem a importância das mídias sociais e das redes sociais para o compartilhamento da informação, uma vez que a quantidade de indivíduos conectados e a quantidade de horas utilizadas por eles na Internet e nos aplicativos sociais e de comunicação são elevadas, fazendo com essa troca aconteça o tempo todo.

Visto a abordagem geral em relação à Sociedade da Informação e aos avanços tecnológicos, bem como sobre as mídias e redes sociais, o próximo tópico abordará o impacto tecnológico na comunicação científica, assim como o uso das mídias sociais e das redes sociais, visando a disseminação e a mensuração do conhecimento acadêmico-científico gerado por distintas comunidades científicas.

\section{COMUNICAÇÃO CIENTÍFICA E A ALTMETRIA}

O avanço das TIC proporcionou mudanças significativas no que se refere ao alcance, a facilidade e a agilidade para a divulgação da ciência (Schweitzer, Rodrigues, \& Varvakis, 2011) e essas mudanças são apresentadas no campo da CI e, uma vez no âmbito da CI, o subcampo que se encarrega de estudar os fenômenos inter-relacionados a esse tipo de comunicação, é denominado de "Comunicação Científica".

\footnotetext{
${ }^{3}$ Jaron Lanier é cientista, músico e escritor. Ficou conhecido pelo trabalho sobre a 'realidade virtual' e por defender o humanismo e a economia sustentável num contexto digital.
} 
A comunicação científica é um processo que objetiva realizar a troca de informações, entre cientistas e entre os cientistas e a sociedade, no intuito de promover o avanço científico, tecnológico, econômico, social e cultural, em cujo processo estão inclusos a produção, a disseminação e o uso da informação. A comunicação científica pode ser realizada em meios formais, nos quais a informação está estruturada e registrada como, por exemplo, em artigos de periódicos, em livros e capítulos de livros, trabalhos em anais de eventos científicos; ou por meios informais, nesse contexto o conhecimento produzido pode ser compartilhado por meio da oralidade, como as palestras, ou por meios registrados que não são convencionais no âmbito da Ciência como, por exemplo, as redes sociais e os blogs (Mueller, 2000; Targino, 2000; Valerioo e Pinheiro, 2008).

O ato de compartilhar a informação é muito importante e tende a aumentar a produtividade de um determinado campo científico e, assim, gera benefícios ao seu coletivo que, por sua vez, contribuem para o avanço do conhecimento. Nesse sentido, o compartilhamento da informação movimenta a rede, e se consolida por meio da troca de informações entre as pessoas, promovendo assim maior visibilidade em relação aos processos que elas vivenciam (Tomaél, 2012).

A Web 2.0 (Web Social) trouxe a possibilidade de as pessoas estarem conectadas e participarem ativamente de uma rede, o que levou ao surgimento das redes sociais, listas de discussões, blogs, microblogs. Esses novos meios para se relacionar e participar da rede chegaram para uma parcela significativa da sociedade, fator que contribuiu para que as mídias sociais ganhassem mais espaço e atenção e, assim, passaram a ser uma importante ferramenta no que diz respeito ao compartilhamento da informação e de ideias, tanto científicas quanto não científicas, como já mencionado anteriormente. Sobre o uso das redes sociais para realizar esse tipo de disseminação, Tomaél et al. (2005, p. 102), complementam que "[...] o espaço em que as redes sociais se constituem e se proliferam são inerentes à informação e ao conhecimento uma vez que são eles que movimentam as redes".

A circulação da informação sempre esteve em pauta na comunidade científica, fazendo com que os pesquisadores passassem a se preocupar em mensurar e mapear a Ciência, a partir da disseminação de suas produções resultantes de suas pesquisas acadêmico-científicas. Nessa perspectiva, a CI se preocupou em estudar, no contexto da "Comunicação Científica", os EMI, que são alicerçados por teorias, métodos e técnicas voltados à mensuração das produções científicas, utilizados para avaliar o conteúdo, medir seu alcance, sua influência e seu impacto nos diversos canais, suportes e fontes utilizados (Noronha e Maricato, 2008; Oliveira e Gracio, 2011; R. F. Araújo, 2015).

Assim sendo, os EMI são abrangentes e se ocupam de diferentes abordagens para a análise de objetos e fenômenos inter-relacionados a finalidades e contextos distintos e, para tal, adotam-se diferentes métodos e técnicas de pesquisa. Para estudar de modo aprofundado essa variedade, bem como acompanhar o processo de modernização dos EMI foram criados alguns subcampos: Altmetria, Arquivometria, Bibliometria, Cibermetria, Cientometria, Informetria, Patentometria e Webometria.

Destaca-se que, por influência das TIC, esse campo de estudo da CI também se desenvolveu, visto que novos meios de comunicação científica foram aparecendo nesse novo contexto eletrônico/digital. O desenvolvimento da $W e b$, por exemplo, deu origem à Webometria, que enfoca principalmente os dados quantitativos voltados para o ambiente Web, bem como a construção e o uso de recursos no que diz respeito à informação e à estrutura na Web (Björneborn, 2004).

A partir do envolvimento do indivíduo na rede, por meio das mídias sociais digitais, que as produções e os resultados de pesquisa poderiam circular livremente sem entraves. Nesse contexto, evidenciou-se a necessidade de uma nova maneira de avaliar a produção científica, que complementasse as formas tradicionais consolidadas e, assim, surgiram as métricas alternativas, foco de análise do mais recente subcampo dos EMI, a Altmetria.

O termo foi proposto por Priem (2010) em uma publicação na sua página pessoal do Twitter, e só se consolidou com a publicação do artigo "Altmetrics: a manifesto" de Priem, Taraborelli, Groth, e Neylon (2010). A Altmetria considera a atenção online das produções científicas recebidas por canais não tradicionais, ampliando-se para além da Ciência, vinculando-a às redes sociais (científicas ou não científicas), microblogs, blogs, gerenciadores de referências.

Gouveia (2013, p. 222) destaca que:

[...] os blogs e micro-blogs, como o Twitter, desempenham um papel de revisão por pares pós-publicação onde os debates sobre os resultados de pesquisa se aquecem e servem inclusive de orientação para a mídia no momento em que uma destas pesquisas se torna pauta.

Segundo Carvalho (2019, p. 1), a Altmetria “[...] leva em conta um conjunto bastante diversificado de indicadores: citações, menções, compartilhamentos e curtidas em mídias sociais, downloads, etiquetagens ou tagueamento (uso de tag), comentários, notícias, reportagens, enciclopédias, sites, bookmarks, visualizações e registro em gerenciadores de referências bibliográficas [...]."

Destaca-se que Altmetria pode coletar vários indicadores de interação online, e esse fator é evidenciado por Nascimento (2017), quando define dez indicadores e os classifica em seis categorias, conforme segue: 1) Visualiza- 
ção/Download; 2) Compartilhamento/Menção; 3) Salvo/Favorito; 4) Resenha/Comentário; 5) Adaptações; e 6) Citações.

Além de complementarem os métodos tradicionais, as métricas alternativas apresentam vantagens nos seguintes pontos, conforme destaca Nascimento (2017): a) Diversidade: visto que trabalha com diversas fontes e produtos, coletando métricas variadas; b) Velocidade: agora é possível fazer a coleta dos dados de modo mais rápido e até mesmo instantaneamente; c) Visibilidade: ampliam a visibilidade das produções científicas e seu impacto; d) Colaboração: conseguem promover a colaboração entre cientistas de diversos campos e lugares da sociedade; e) Implementação: é possível trabalhar com dados abertos e há ferramentas disponíveis para isso.

No entanto, ainda existem limitações, até porque trata-se de um subcampo recente no contexto científico e, portanto, precisa ser mais explorado. Nascimento (2017) aborda tais barreiras e, entre elas, destaca: a) a necessidade de uma maior adoção de pesquisa online; b) as dificuldades técnicas e tecnológicas para a implementação; c) a possibilidade de manipulação dos dados de citação. Sabe-se que os pesquisadores têm certa resistência em relação ao uso desses meios alternativos para divulgação de seus trabalhos, assim essa promoção ou até mesmo autopromoção ocorre de maneira mais lenta.

Assim como os subcampos mais consolidados dos EMI, a Altmetria ganha espaço em eventos nacionais e internacionais específicos dos EMI, bem como do campo científico da CI, sendo exemplo o Encontro Nacional de Pesquisa em Ciência da Informação (ENANCIB), cujos estudos são apresentados no âmbito do Grupo de Trabalho 7 - Produção e Comunicação da Informação em Ciência, Tecnologia \& Inovação, bem como o Encontro Brasileiro de Bibliometria e Cientometria (EBBC), e o Latmétricas que é resultado da junção dos eventos LATmetrics e Simpósio Latino-Americano de Estudos Métricos em Ciência e Tecnologia.

Além do contexto dos eventos, as métricas alternativas e seus indicadores ganharam manuais e instruções de uso, elaborados pela National Information Standards Organization (NISO) (National information standards organization, 2019). Ainda, Nascimento (2017) desenvolveu um guia para auxiliar o uso da Altmetria por bibliotecários, e mais recentemente essa questão foi apresentada no livro Tópicos da bibliometria para bibliotecas universitárias (Grácio, Martínez-Ávila, Oliveira, \& Rosas, 2020).

As métricas alternativas ressaltam a possibilidade de estudar como a produção científica circula nas mídias sociais, e em alguns casos já são utilizadas para compartilhar o conhecimento científico com efetividade, podendo inclusive impactar e auxiliar diretamente no processo de avaliação da produção e da produtividade científica. Nota-se, portanto, que a ciência e, em específico a comunicação científica, vem se mantendo atualizada e sofre os impactos dos avanços tecnológicos que ocorrem no mundo de modo geral, principalmente no contexto da Sociedade da Informação.

\section{CONSIDERAÇÕES FINAIS}

A partir da Revolução Industrial e da consolidação da Sociedade da Informação, o mundo entrou em uma nova Era Informacional, tendo a informação e a tecnologia como elementos centrais, movimentando discussões sobre o que é informação, evidenciando que a informação é um fenômeno complexo.

Os avanços tecnológicos impactaram o mundo, seja positivamente, seja negativamente, e atualmente a tecnologia faz parte da vida de cada indivíduo. No âmbito digital, esses avanços possibilitaram estabelecer conexões entre pessoas que possuem gostos similares, aproximando indivíduos de distintas regiões do mundo, e isso foi possibilitado por meio do surgimento das mídias sociais.

No entanto, essa tecnologia influi sobremaneira no comportamento das pessoas, inclusive manipulando e rastreando os interesses de cada indivíduo, bem como gerando certa dependência tecnológica. Além disso, interferem na quantidade e na qualidade de informação disseminada, evidenciando a fragilidade em relação à transparência e veracidade dos conteúdos veiculados. Todavia, de modo geral as tecnologias proporcionam a inter-relação humana, como nunca antes havia sido proporcionada.

No âmbito da ciência foi preciso acompanhar os avanços que ocorreram na sociedade e, no que diz respeito ao campo da CI, isso também aconteceu. Destaca-se que estudar os fenômenos afetos à comunicação científica e, por conseguinte, à mensuração da produção científica nos mais variados canais como, por exemplo, nas mídias sociais, se tornou fator preponderante para o desenvolvimento da área. Assim, surgem as variantes nos EMI, cujos novos subcampos criados, visam atender esses novos canais da comunicação científica, entre eles o mais recente deles, a Altmetria, que estuda a comunicação científica em contextos alternativos, como as redes sociais, sejam elas científicas ou não científicas.

Esse movimento demonstra, na perspectiva de Mattelart (2002, p. 105), que "[...] o saber pós-moderno é ambivalente. Ele é ao mesmo tempo um novo instrumento de poder e uma abertura para as diferenças".

Ressalta-se que esses avanços são necessários para que a sociedade não fique estagnada, assim como a ciência, consolidando o constante progresso e, para tanto, é necessário utilizar a tecnologia a seu favor, de modo 
consciente e consistente. Tanto cientistas, quanto indivíduos fora deste meio, precisam desenvolver competências em informação para lidar eficientemente com esses novos mecanismos de comunicação. 


\section{REFERÊNCIAS}

Araújo, C. A. Á. (2014). O que é ciência da informação? Informação \& Informação, 19(1), 01-30. Recuperado de http://www.uel.br/revistas/uel/index.php/informacao/ article/view/15958

Araújo, R. F. (2015). Estudos métricos da informação na web e o papel dos profissionais da informação. Bibliotecas Universitárias: Pesquisas, Experiências e Perspectivas, 2(1), 42-64. Recuperado de https://www.researchgate.net/publication/ 272943595 Estudos metricos da informacao na web _e_o_papel_dos_profissionais_da_informacao

Björneborn, L. (2004). Small-world link structures across an academic web space: a library and information science approach (Tese de pós-doutorado). Royal School of Library and Information Science, Denmark.

Braga, R. (2016). O excesso de informação: a neurose do século xxi. Recuperado de https://docplayer.com.br/3804688 -O-excesso-de-informacao-a-neurose-do-seculo-xxi.html

Carvalho, B. L. P. (2019). O que é altmetria? repensando o impacto da pesquisa acadêmica. Blog PPEC, 3(2). Recuperado de https://periodicos.sbu.unicamp.br/blog/index.php/ 2019/03/31/altmetria/

Dziekaniak, G., \& Rover, A. (2011). Sociedade do conhecimento: características, demandas e requisitos. Revista de Informação, 12(5). Recuperado de http://hdl.handle.net/ 20.500.11959/brapci/7461

Gil, A. C. (2008). Métodos e técnicas de pesquisa social (6a. ed.). São Paulo: Atlas.

Gouveia, F. C. (2013). Altmetria: métricas de produção científica para além das citações. Liinc em revista, 9(1). Recuperado de http://revista.ibict.br/liinc/article/view/3434/ 3004

Grácio, M. C. C., Martínez-Ávila, D., Oliveira, E. F. T., \& Rosas, F. S. (2020). Tópicos da bibliometria para bibliotecas universitárias. São Paulo: Editora Oficina Universitária.

Guattari, F., \& Micropolítica, R. S. (1996). Micropolítica: Cartografias do desejo (7a. ed.). Petrópolis: Vozes.

Hardt, M., \& Negri, A. (2004). Guerra: Simplicissimus. In Multitud: guerra y democracia en la era del imperio ( $\mathrm{p}$. 21-59). Barcelona: Debate.

Ilharco, F. (2003). Filosofia da informação: uma introdução à informação como fundação da acção da comunicação e da decisão. Lisboa: Universidade Católica Editora.

Kaplan, A. M., \& Haenlein, M. (2010). Users of the world, unite! the challenges and opportunities of social media. Business horizons, 53(1), 59-68. doi: https://doi.org/10.1016/j.bushor.2009.09.003

Kemp, S. (2020). Digital 2020: 3.8 billion people use social media. We are social. Recuperado de https://wearesocial.com/blog/2020/01/digital-2020-3-8 -billion-people-use-social-media

Kemp, S. (2021). Digital 2021: the latest insights into the 'state of digital'. We are social. Recuperado de https://wearesocial.com/blog/2021/01/digital-2021-the -latest-insights-into-the-state-of-digital

Kotler, P., \& Keller, K. L. (2012). Administração de marketing (14a. ed.). São Paulo: Person Education do Brasil.

Lanier, J. (2018). Dez argumentos para você deletar agora suas redes sociais. Rio de Janeiro: Editora Intrinseca.
Marteleto, R. M. (2010). Redes sociais, mediação e apropriação de informações: situando campos, objetos e conceitos na pesquisa em ciência da informação. Pesquisa Brasileira em Ciência da Informação, 3(1), 27-46. Recuperado de https://brapci.inf.br/index.php/article/download/13080

Mattelart, A. (2002). História da sociedade da informação. São Paulo: Loyola.

Mueller, S. P. M. (2000). O periódico científico. In Fontes de informação para pesquisadores e profissionais (p. 73-95). Belo Horizonte: UFMG.

Musso, P. (2006). Ciberespaço, figura reticular da utopia tecnológica. In Sociedade midiatizada. Rio de Janeiro: Mauad.

Nascimento, A. G. (2017). Altmetria para bibliotecários: guia prático de métricas alternativas para avaliação da produção científica. Rio de Janeiro: Scortecci.

National information standards organization. (2019). Niso alternative assessment metrics (altmetrics) initiative. Recuperado de https://www.niso.org/standards-committees/ altmetrics

Noronha, D. P., \& Maricato, J. M. (2008). Estudos métricos da informação: primeiras aproximações. Encontros Bibli: revista eletrônica de biblioteconomia e ciência da informação, 13(1), 116-128. doi: https://doi.org/10.5007/15182924.2008v13nesp1p116

O Dilema das Redes. (2020). Direção: Jeff Orlowski. Produção: Larissa Rhodes. Estados Unidos. Netflix. (89 min)

Oliveira, E. F. T. d., \& Gracio, M. C. C. (2011). Indicadores bibliométricos em ciência da informação: análise dos pesquisadores mais produtivos no tema estudos métricos na base scopus. Perspectivas em Ciência da Informação, 16(4), 16-28. doi: http://dx.doi.org/10.1590/S141399362011000400003

Ponto de Mutação. (1990). Direção: Bernt Amadeus Capra. Produção: A. J. Cohen. Whashington: Triton Pictures. Recuperado de https://www.youtube.com/watch?v= 72JHi0eEvJA (1 vídeo, $112 \mathrm{~min}$ )

Priem, J. (2010). Altmetrics. Vancouver: Twitter. Recuperado de https://twitter.com/jasonpriem/status/ 25844968813

Priem, J., Taraborelli, D., Groth, P., \& Neylon, C. (2010). Altmetrics: a manifesto. Recuperado de http://altmetrics .org/manifesto

Recuero, R. (2016). Redes sociais na internet. Porto Alegre: Sulina.

Reis, E. V., \& Tomaél, M. I. (2017). A geração ze as plataformas tecnológicas. Informação \& Informação, 22(2), 371-388. doi: http://dx.doi.org/10.5433/1981-8920.2017v22n2p371

Resultados Digitais. (2020). Redes sociais. Recuperado de https://resultadosdigitais.com.br/especiais/tudo-sobre -redes-sociais/

Schweitzer, F., Rodrigues, R. S., \& Varvakis, G. J. (2011). Comunicação científica e as tecnologias de informação e comunicação. Comunicação \&s Sociedade, 32(55), 83-104. Recuperado de https://www.metodista.br/revistas/revistas -metodista/index.php/CSO/article/view/1633

Targino, M. G. (2000). Comunicação científica: uma revisão de seus elementos básicos. Informação ES Sociedade, 10(2). Recuperado de https://periodicos.ufpb.br/ojs2/index.php/ ies/article/view/326

Tomaél, M. I. (2012). Categorias e dimensões do com- 
partilhamento da informação. In Compartilhamento da informação (p. 13-40). Londrinas: Eduel.

Tomaél, M. I., Alcará, A. R., \& Di Chiara, I. G. (2005). Das redes sociais à inovação. Ciência da informação, 34 (2), 93104. Recuperado de https://www.brapci.inf.br/index.php/ res/v/21277

Valerioo, P. M., \& Pinheiro, L. V. R. (2008). Da comunicação científica à divulgação. Transinformação, 20(2), 159-169. doi: https://doi.org/10.1590/S010337862008000200004

Como citar este artigo (APA):

Delbianco, N. R, \& Valentim, M. L. P. (2022). Sociedade da Informação e as mídias sociais no contexto da comunicação científica. AtoZ: novas práticas em informação e conhecimento, 11, 1 - 11. Recuperado de: http://dx.doi.org/10.5380/atoz.v11.78778 


\section{NOTAS DA OBRA E CONFORMIDADE COM A CIÊNCIA ABERTA}

\section{CONTRIBUIÇÃO DE AUTORIA}

\begin{tabular}{|l|c|c|}
\hline $\begin{array}{l}\text { Papéis } \\
\text { e contribuições }\end{array}$ & $\begin{array}{c}\text { Natalia Rodrigues } \\
\text { Delbianco }\end{array}$ & $\begin{array}{c}\text { Marta Lígia Pomim } \\
\text { Valentim }\end{array}$ \\
\hline Concepção do manuscrito & X & X \\
\hline Escrita do manuscrito & X & X \\
\hline Metodologia & X & \\
\hline Curadoria dos dados & X & \\
\hline Discussão dos resultados & X & \\
\hline Análise dos dados & X & \\
\hline
\end{tabular}

\section{FINANCIAMENTO}

$\mathrm{O}(\mathrm{s})$ autor(es) declara $(\mathrm{m})$ que esta pesquisa recebeu financiamento conforme dados indicados a seguir e o documento comprobatório foi anexado como documento suplementar: A pesquisa recebeu financiamento da Coordenação de Aperfeiçoamento de Pessoal de Nível Superior (CAPES).

\section{Disponibilidade de Dados Científicos da Pesquisa}

Os conteúdos subjacentes ao texto da pesquisa estão contidos no manuscrito.

\section{EQUIPE EDITORIAL}

\section{Editora/Editor Chefe}

Maria do Carmo Duarte Freitas (https://orcid.org/0000-0002-7046-6020)

\section{Editora/Editor Associada/Associado}

Paula Carina de Araújo (https://orcid.org/0000-0003-4608-752X)

Helza Ricarte Lanz (https://orcid.org/0000-0002-6739-2868)

\section{Editora/Editor de Texto Responsável}

Byanca Neumann Salerno (https://orcid.org/0000-0002-1609-4684)

Cristiane Sinimbu Sanchez (https://orcid.org/0000-0002-0247-3579)

Editora/Editor de Layout

Felipe Lopes Roberto (https://orcid.org/0000-0001-5640-1573) 